\title{
The body revealed
}

67 he human body is the most magnificent piece of art." How many medical stu-

dents have heard this phrase uttered by an anatomy professor or a neurologist in awe of the human brain? Like most platitudes, there is an underlying truth to this statement, a truth that is revealed by Chantal Gervais in her exploration of the innate aesthetics of the human body through the artistic use and rendition of medical imagery.

The Ottawa-based artist and photography professor's work was recently presented in the Montréal, Quebec exhibition $R x$, with 2 other artists who are likewise fascinated with the human body. ${ }^{1}$ Gervais' art series - Les maux non dits — are the latest works in her exploration of "the effects on the body of aging, accidents, disease and life itself, and how our perception of the body is influenced and altered by popular culture, art, science and medicine." ${ }^{\prime 2}$ She presents the body her body — in life-size complex images that elicit a wide range of emotions and thoughts.

Looking at her works "Autoportrait 1" and "Autoportrait 3" is quite disturbing to the clinician: the eye is drawn to the global image of a life-sized woman through a juxtaposition of magnetic resonance imagery, but the physician's eyes are attracted to all the little details of organs, flesh or bone thus represented. A proliferation of details of different density suggests a mosaic. At first take, "Autoportrait 3" appears to be the negative of the first. However, a closer look reveals that only the outside shape is similar; the inside changes depending on the perspective. Some organs are very well delimited, others barely visible and some are not seen at all. The inner architecture is enhanced by use of contrast and by the choice of which layers are exposed.

The focal point of the exhibit is Gervais' rendition of the "Vitruvian Man," in which she reinterprets the ubiquitous Da Vinci drawing, transforming it into "Vitruvian Me"- a woman in all her splendour. Da Vinci's drawing, which adhered to the utmost scientific rigour - it aimed at creating the "canon of human proportion" - is counterbalanced by Gervais' work, which uses modern scientific techniques and imagery to reveal the inner body. The proliferation of details gives 8 an impression of fragility to the otherwise overwhelming work. Just like diagnostic imagining, the longer you examine it, the more details are revealed, and the more the work differs from Da Vinci's masterpiece. The smooth drawing is transformed in symmetrical assemblages of squares, almost pixel like. The head is not midline, but looking on one side — or are there 2 heads?

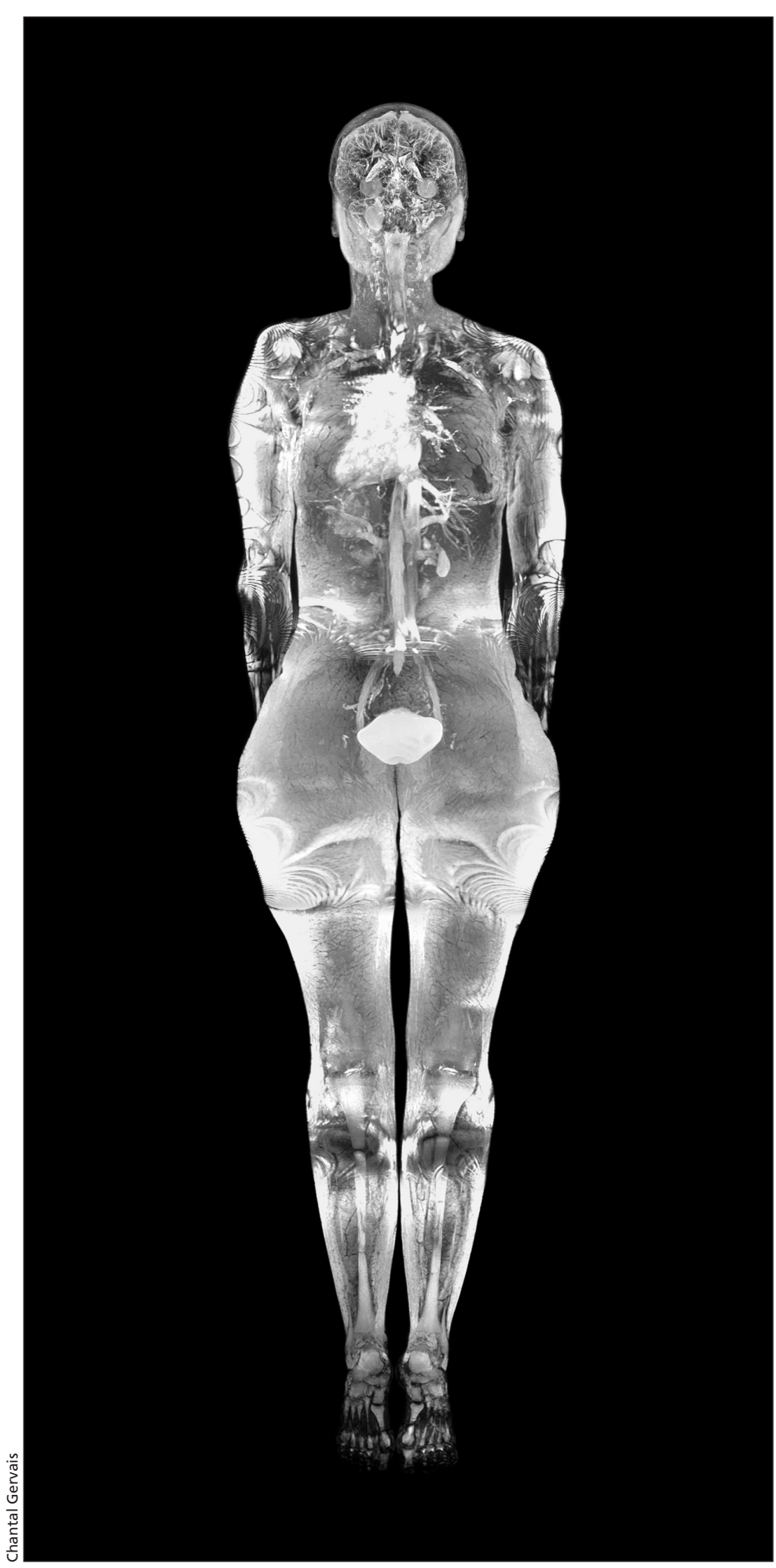

Chantal Gervais, "Autoportrait 1" (2008) from Les maux non dits. Inkjet print on polypropylene. $207 \times 102 \mathrm{~cm}$. Artist's collection. 


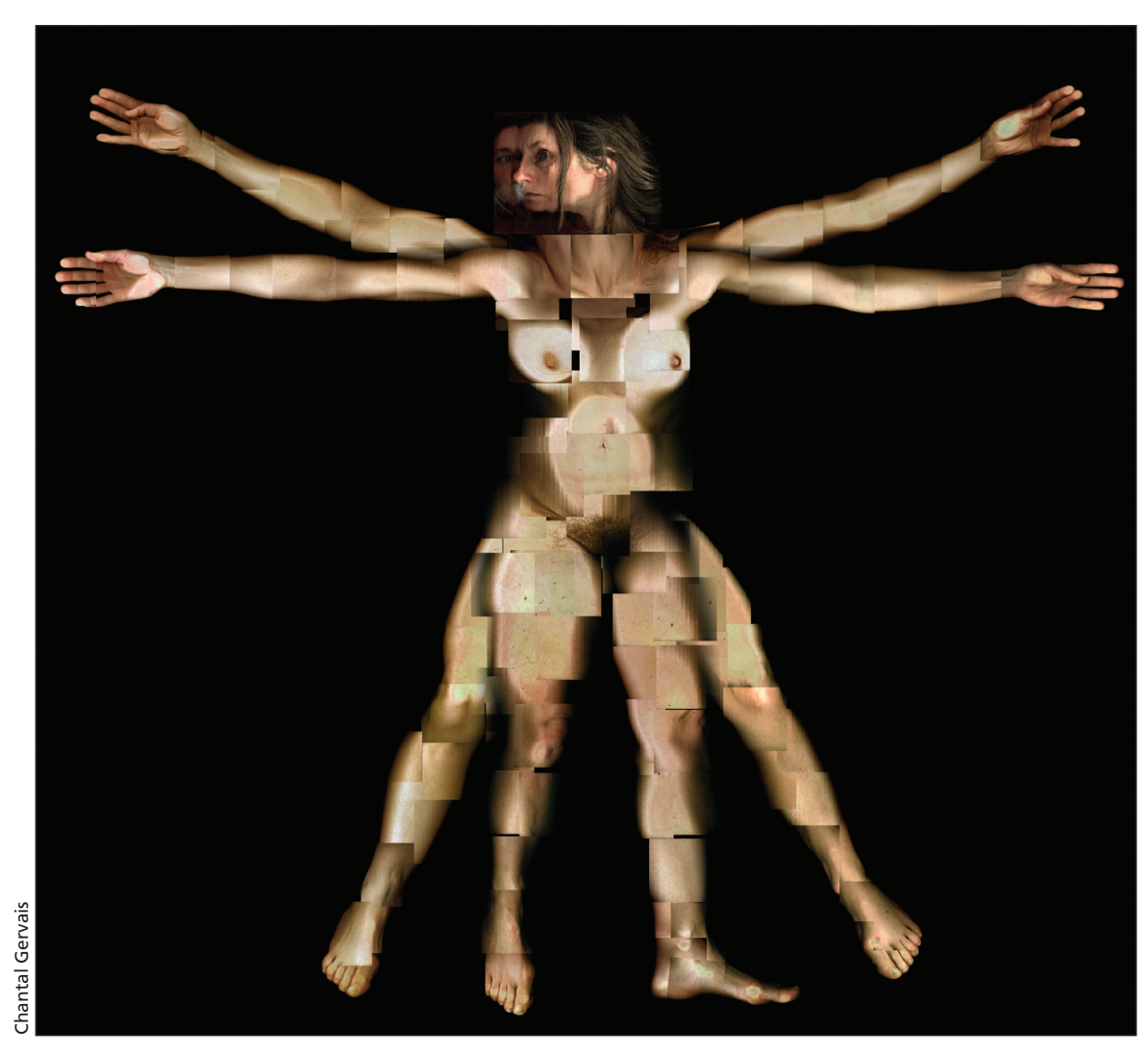

Chantal Gervais, "Vitruvian Me"(2008) from Les maux non dits. Inkjet print on polypropylene. $152 \times 172 \mathrm{~cm}$. Artist's collection.
Yellow spots mark the heels: could the Vitruvian woman have blisters?

One leaves the exhibit with mixed feelings. The inner beauty of the human body, its fragility, its profound aesthetic impact is clear. We are reminded of prehistoric Venus figurines, of silhouettes that children trace of themselves with markers onto large strips of paper: There is a definite impression of primitive art. However, at the same time, modern technology is at the core of Gervais' work; it could not exist without MRI and flatbed scans. This powerful duality destabilizes and intrigues, and by changing our view of the body could change our view of the world.

\section{Isabelle Leblanc MD \\ Family medicine \\ McGill University \\ Montréal, Que.}

\section{REFERENCES}

1. Gervais C, Stelmackowich C, Sudhoff S. Rx. IPS Exhibitions. Montréal (QC): 2009. Available: www .inplainsight.ca/en/exhibitions/2009/04/rx/index.php (accessed 2009 May 11).

2. Gervais C. Artist's website. Ottawa (ON); 2009. Available: www.artengine.ca/cgervais/ (accessed 2009 May 11).

\section{Health disparities grow as people live longer}

\author{
Global Health and Global Aging \\ Mary Robinson, William Novelli, Clarence \\ Pearson and Laurie Norris, editors \\ Jossey-Bass; 2007. \\ 373 pp \$55.00 (e-book available)
}

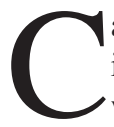

algary is aging, Canberra is aging, Calcutta is aging. The

world's population is getting older and it is doing so in almost every country. And if you harboured any doubts about this, take a quick look at this book. In 1949, the year I was born, the global population aged 60 or more accounted for only $8 \%$ of the total. By the time I die, say in 2070 , that figure will rise to $22 \%$. This forecast is both good and bad news, and this book examines both.
To begin with the half-full metaphor, the growth in the number of older folks is a paean to mankind's success in mitigating premature mortality — an absolute first in world history. Almost all of us want to live longer and now more actually do.

However, under the half-empty rubric, the aging of the population presents 2 major problems (happily, both are at least partially correctable through a combination of lifestyle choices and modern medicine).

The first problem involves the overall increase in the burden of age-related disease. While relatively, many older folks are staying healthier and often dying before they get sick, there are still, from an absolute point of view, more older people, some of whom will fall ill. Ergo, the world will have to cope with an overall increase in age-related disease and illness.

The second bit of bad news is that old age in the District of Columbia is not the same as old age in the State of Colombia. As is the case with another vulnerable group, children, we see that disparities in wealth and education translate almost directly into gaps in health status for older folks.

It may sound obvious, but very poor and old people in developing countries, have a much more difficult time of it than their counterparts in the developed world. As well, the dizzying speed of demographic change makes it difficult for many countries to cope. For example, it took almost 140 years for France's senior population to rise from $10 \%$ to $20 \%$ of the total. In contrast, it will take India 